\title{
Laboratório virtual como alternativa didática para auxiliar o ensino de química no ensino médio
}

\author{
Title: Virtual laboratory as didactic alternative for teaching in chemistry in high \\ school \\ Guilherme Leocárdio Lucena \\ Universidade Federal da Paraíba \\ João Pessoa, PB, Brasil \\ guilherme_leo1@yahoo.com.br \\ Vandeci Dias dos Santos \\ Universidade Estadual da Paraíba \\ Campina Grande, PB, Brasil \\ vandeci@yahoo.com.br \\ Afranio Gabriel da Silva \\ Universidade Federal da Paraíba \\ João Pessoa, PB, Brasil \\ agasil@yahoo.com
}

\begin{abstract}
Resumo Sendo a atividade experimental em Química uma prática indispensável no processo de construção do conhecimento desta ciência, a ausência de equipados e modernos laboratórios é o principal motivo no distanciamento entre o ensino teórico e a prática, problema este vivenciado pela maioria das escolas de Ensino Médio no Brasil. Devido à crescente globalização da informação e à necessidade de melhoria na qualidade do ensino, surge a necessidade em utilizar novas metodologias no processo educacional, de forma a despertar o interesse do aprendiz. Este trabalho apresenta a utilização de laboratórios virtuais, que simulam experimentos químicos, como recurso didático-pedagógico para auxiliar o professor na prática docente de química por meio da realização de atividades experimentais no ensino médio. Verificou-se que a utilização do software educacional de química provocou grande aprovação por parte do corpo escolar consultado. No que se refere ao melhoramento da aprendizagem, a utilização do recurso computacional contribuiu de forma significativa na compreensão dos conteúdos pelos discentes e possibilitou a relação entre teoria e prática.
\end{abstract}

Palavras-Chave: Atividade experimental, Ensino de química, Laboratório virtual

\begin{abstract}
The experimental activity is an indispensable practice in the process of knowledge development in chemistry and the lack of modern and equipped laboratories is one of the main reasons of the separation between theoretical approach and the practical one. This problem is experienced by most of high schools in Brazil. Due to the growing of globalizing information and the need to improve the quality of education, there is a growing interest in the using of new methods in the educational process, in order to arouse the interest of the learner. This study describes the use of virtual labs, which simulate chemical experiments, as a didactic-pedagogic instrument, to help teachers to conduct experimental activities in high schools. It was found that the use of educational software for teaching chemistry has led to a great approval by the academics consulted. Regarding the enhancement of learning, the use of the computational resources contributed significantly the understanding of the content by the students, allowing the better relationship between theory and practice.
\end{abstract}

Keywords: Experimental activity, teaching chemistry, Virtual Lab. 


\section{Introdução}

As escolas estão cada vez mais se modernizando através da informática, e este mecanismo de modernização vem se desenvolvendo de maneira muito rápida, através de computadores e programas mais sofisticados. A intensidade com que a informática se desenvolveu nos últimos anos, permitiu um avanço crucial na qualidade do ensino, principalmente por ser um instrumento que desperta a atenção dos discentes [1]. A introdução de novas tecnologias computacionais tem proporcionado uma alternativa promissora para um crescimento significativo no processo de ensino-aprendizagem, auxiliando assim os docentes e facilitando a compreensão dos discentes.

Muitos são os países que utilizam as Tecnologias da Informação e Comunicação (TICs) aplicadas à educação. Esse feito faz parte da era da informação que afeta a quase todas as atividades humanas mediante a utilização da internet, correios eletrônicos e de outras ferramentas computacionais $[2,3]$.

De forma geral, o ensino de química requer, tanto do professor quanto do aluno, que a teoria discutida e trabalhada em sala de aula seja experimentada, confirmada e, sobretudo, que possa existir uma construção de conhecimento e não uma mera repetição de teorias e crenças. Diante desta realidade, faz-se necessário a aquisição laboratórios devidamente equipados para que assim as escolas possam oferecer recursos necessários para que o profissional da educação química possua soluções didáticas para exercer sua função de facilitador na construção do conhecimento.

Porém, a realidade educacional brasileira é bem diferente da necessidade real vivenciada pelos professores da educação básica. Na maioria das escolas, principalmente da rede pública, os únicos recursos pedagógicos disponíveis se resume ao giz e ao apagador. A ausência de políticas públicas que proporcione à melhoria da qualidade educacional brasileira é a principal causa de tais problemas.

Na prática, o ensino de química nas escolas se baseia no verbalismo teórico-conceitual totalmente desvinculado do cotidiano dos alunos. Os estudantes do Ensino Fundamental e Médio, muitas vezes, encontram dificuldades no desenvolvimento de idéias de caráter interdisciplinar, em função de terem sido formados dentro de visão positivista e fragmentada do conhecimento [4].

A realização de atividades químicas experimentais é considerada uma prática indispensável no processo de ensino-aprendizagem, principalmente no setor da educação básica. A construção do conhecimento a partir da observação e da descoberta por meio de hipóteses e conclusões empíricas contribui para a formação de cidadãos com consciência mais crítica e capazes de racionalizar melhor nas mais diversas situações do cotidiano. A escola deve ser o local privilegiado neste processo de construção, oferecendo ambientes físicos favoráveis e recursos didáticos essenciais, permitindo a troca de experiências e a discussão para um entendimento comum e aceitável dos fenômenos estudados. Também os docentes devem estar motivados e preparados para assegurar a melhor metodologia pedagógica necessária.

De acordo com as diretrizes dispostas nos Parâmetros Curriculares Nacionais para a Química (PCNs) [5], o ensino desta ciência presencia um paradigma inviável e ineficaz em todos os níveis, mas, sobretudo, no âmbito superior. Desta forma, se defende no citado documento, a necessidade de criação de um novo modelo de curso superior, que privilegie o papel da importância do estudante no processo da aprendizagem, em que a função do professor, de "ensinar coisas e soluções", passe a ser "ensinar o estudante a aprender coisas e soluções" [3]. Nesta realidade, as TICs propõe um excelente meio para introduzir práticas pedagógicas que favoreçam a participação ativa do aluno no processo mencionado

A utilização de recursos computacionais é uma estratégia didática que minimiza a deficiência encontrada na maioria das escolas. O uso de softwares educacionais que simulam experimentos reais tem sido uma alternativa para que o professor de química possua o mínimo de recurso didático para ministrar uma aula experimental.

Além de reduzir a deficiência das aulas experimentais, o uso de softwares químicos educacionais é um recurso dinâmico que atraem a curiosidade e a busca pela descoberta da ciência em estudo por parte dos discentes, uma vez que estes softwares possuem animações que simulam experimentos muito próximos da realidade [6]. Dentre as várias opções de softwares químicos educacionais, os laboratórios virtuais destacam-se devido o aluno ter a capacidade de navegar por um Laboratório tridimensionalmente modelado, interagindo com seus objetos: vidrarias, equipamentos, reagentes, etc.

Nesta perspectiva, este trabalho buscou avaliar a utilização de um laboratório virtual nas aulas de química em uma escola pública situada na cidade de Campina Grande/PB com o objetivo de proporcionar a construção do conhecimento dos fenômenos químicos através da observação e investigação.

Os objetivos específicos desta investigação buscaram verificar os possíveis impactos positivos que a ferramenta computacional poderia oferecer e o grau de aprovação do recurso digital por parte dos docentes. 


\section{Fundamentação Teórica}

\subsection{O computador como ferramenta de ensi- no}

Em um passado não tão distante, ao se mencionar o uso do computador na prática educacional o primeiro entendimento era que a máquina substituiria o professor. Em tempos hodiernos, este "mito" já não faz parte do entendimento dos docentes no que diz respeito à importância que a informática exerce sobre a educação. O processo educacional munida das inovações da informática vem tornar o exercício da construção do conhecimento uma atividade bem mais atrativa, proporcionando a busca pela compreensão através da observação além de favorecer uma visão um pouco mais além daquela disposta nos livros didáticos e na discussão interclasse.

Atualmente o computador tornou-se um aliado inseparável dos estudantes, pois proporciona uma maior comodidade e agilidade nas necessidades diárias, como por exemplo, o acesso rápido e eficaz a acervos bibliográficos (antes detidos nas grandes bibliotecas) informações em tempo real, etc. No ensino superior, mais precisamente, é indispensável à utilização da máquina como recurso didático, seja no simples ato de digitar um trabalho ou na busca por informações ainda restrita nos livros.

Toda e qualquer tecnologia que possui potencialidades e características de comunicação e manipulação de informações, parece adequar-se perfeitamente as atividades ligadas à educação, na medida em que o ato de ensinar/aprender consiste, sobretudo, em uma relação de comunicação por excelência $\mathrm{A}$ introdução de novas tecnologias na educação vem aprimorando o conhecimento, no sentido de que assume a forma de objeto didático auxiliar no ensino, sendo capaz de gerar e proporcionar aos seus usuários a transmissão de conhecimentos científicos de maneira lúdica [7].

A melhor forma de aprender é interagir, seja com a máquina, com a tecnologia, com as telecomunicações, com os colegas ou mesmo com os professores. Aos alunos interessa tanto o aprendizado por instrução como por descoberta. Não podemos dispensar nem um recurso nem outro. O que precisa haver é a ideal comunhão entre esses elementos que estimulam o aprendizado. Se o professor se aliar adequadamente aos recursos que lhe estão disponíveis, todos têm a ganhar [8].

O emprego do computador, quando bem dirigido, possui um grande poder de persuasão junto aos alunos, pois, ao mesmo tempo em que diverte, instrui. É uma das fantásticas maneiras de se aprender, utilizando-se as novas tecnologias de ensino-aprendizagem, sem as limitações de uma simples aula expositiva numa sala de aula convencional [1]. Através dessa ferramenta podemos atribuir memória a um banco de dados, criar simulações, percepção de realidades virtuais etc.

A sofisticação e acessibilidade dos programas computacionais tornaram a interação homem-máquina muito mais rápida e familiar. Sendo assim, os indivíduos estão buscando a cada dia atualizar-se e possuírem o que há de mais inovador no âmbito da informática.

Os programas utilizados na educação devem promover a maior interação possível entre o computador e o estudante, possibilitando-lhe também expressar o seu próprio saber para o desenvolvimento de suas tarefas [1].

Dentre os vários tipos de softwares dispostos no mercado pode-se fazer menção aos ditos: softwares tutoriais (versões computadorizadas das conhecidas aulas tradicionais); softwares de jogos educacionais (atua como uma ferramenta desafiadora na motivação da construção do saber); softwares de simulação (permite uma interatividade e a possibilidade de simular situações experimentais e visualizar fenômenos de caráter microscópicos, muitas vezes impossíveis de compreender mesmo em uma aula prática experimental). Dos tipos de softwares citados este último apresenta uma vantagem em relação aos outros, pois permite a exploração de situações fictícias e de risco. Em Química, por exemplo, é possível trabalhar com materiais radioativos e não é necessária a contaminação de um lago para propor os métodos adequados para sua despoluição.

Pessoa [9] afirma que, tais softwares apresentam potencial educacional mais ambicioso que os programas tutoriais, porém podem desenvolver uma visão distorcida da realidade, trazendo uma visão simplista do mundo. Quando há grande possibilidade de interação com o computador, esse tipo de software faz com que tal recurso seja mais usado como ferramenta do que como um tutor do conhecimento. Esse é o caso que observamos em simuladores de vôo e em outros tipos de simuladores com finalidade educativa.

Para Schank [10], "a metodologia de Aprender Fazendo Baseado em Simulações faz com que o aluno adquira habilidades através do aprendizado, pois, quando se realiza uma tarefa simulada, se está aprendendo a forma de execução e se pode utilizar este conhecimento para atividades da vida real. Isto é muito importante, pois faz com que o aluno sinta a aplicabilidade do aprendizado em momentos de seu interesse".

\subsection{Presença da informática na formação docente de química no Brasil}

A formação de docentes capacitados a utilizarem tecnologias da informática na educação química, não exige 
apenas o domínio dos recursos, mas uma prática pedagógica reflexiva. Neste sentido, Gabini e Diniz [11] afirmam que:

"A escola deve adaptar-se e abrir-se para as possibilidades geradas pelas tecnologias, não ignorando ou desafiando essa presença atual, o que provocaria um distanciamento do ensino desenvolvido e as novas linguagens. Contudo, reforça-se a importância de não agir de forma acrítica e alienada em relação aos recursos. O potencial das tecnologias digitais no contexto educacional determina oportunidades adicionais aos alunos, ampliando os limites da sala de aula. A contribuição que os recursos tecnológicos, em especial a informática, têm trazido ao ensino de Química, por exemplo, por meio das simulações, pode colaborar para a reversão de uma situação de afastamento desenvolvida por parte dos alunos em relação ao monólogo do professor treinando macetes e dicas de como decorar fórmulas e nomes de substâncias".

Nesse sentido, os docentes necessitam não apenas conhecer o recurso didático e o conteúdo programado. É necessário promover uma reflexão sobre qual a melhor maneira de introduzir o recurso em seu cotidiano.

"O uso do computador expressa-se em um contexto de contínua interação. Nesse sentido, o computador não é apenas um instrumento que prolonga nossos poderes de comunicação ou de processar informações: realiza operações e interpreta informações de modo correspondente ao nosso. Com isso possibilita uma qualidade de interação, que tem valor de desenvolvimento. Piaget chamava essa qualidade dialética de interação de 'formas de interdependência'. Trata-se de uma interação em que os elementos devem funcionar ao mesmo tempo, como 'todo' e como 'parte', ou seja, devem atuar de forma interdependente. Como 'todo' porque são 'responsáveis' por suas decisões, e como 'parte', porque sua ação depende da ação de um outro. Não é assim, entre nós e um programa de computador? Não deveria ser assim, também, na escola?" [8].

Pessoa [9] ao estudar as grades curriculares e ementas das disciplinas dos cursos de licenciatura em química das Universidades Federais do Brasil (UF) mostra os seguintes dados apresentados na Tabela 1 .
Tabela 1. Observação em relação à presença da Informática nos cursos de licenciatura em Química no Brasil.

\begin{tabular}{|c|c|}
\hline Região Geográfica & Observações \\
\hline Norte & $\begin{array}{l}\text { Cursos de duas UF's possuem a } \\
\text { disciplinas envolvendo informá- } \\
\text { tica, porém nenhuma delas visa } \\
\text { aplicação direta no ensino de } \\
\text { química - EQ. }\end{array}$ \\
\hline Nordeste & $\begin{array}{l}\text { Duas UF's apresentam discipli- } \\
\text { nas envolvendo informática sem } \\
\text { relação direta com o ensino de } \\
\text { química, uma possui uma disci- } \\
\text { plina que visa o uso do compu- } \\
\text { tador como ferramenta para o } \\
\text { estudo da química e outras qua- } \\
\text { tro apresentam disciplinas de } \\
\text { informática relacionadas ao EQ. }\end{array}$ \\
\hline Centro-oeste & $\begin{array}{l}\text { Duas UF's possuem disciplinas } \\
\text { de informática sem relação } \\
\text { direta com o EQ. }\end{array}$ \\
\hline Sudeste & $\begin{array}{l}\text { Seis UF's possuem disciplinas } \\
\text { de informática sem relação } \\
\text { direta com o EQ, uma UF possui } \\
\text { uma disciplina que visa o uso do } \\
\text { computador como ferramenta do } \\
\text { EQ e outras três que apresentam } \\
\text { em seus fluxogramas disciplinas } \\
\text { de informática com relação } \\
\text { direta ao EQ. }\end{array}$ \\
\hline Sul & $\begin{array}{l}\text { Três UF's possuem disciplinas } \\
\text { de informática sem relação } \\
\text { direta com o EQ, uma apresen- } \\
\text { tando a informática como ferra- } \\
\text { menta para o EQ e duas com } \\
\text { disciplinas que possuem relação } \\
\text { direta entre os mesmos. }\end{array}$ \\
\hline
\end{tabular}

A possibilidade da utilização da informática no ensino de Química na formação inicial de professores possibilita a estes profissionais, o desenvolvimento e aprimoramento de habilidades para o uso criativo da informática em suas práticas docentes. Desta forma, as TICs podem oportunizar, facilitar e estimular mudanças no processo tradicional de ensino, centrado no professor e na transmissão de conteúdos para processos de ensino-aprendizagem que buscam focar as ações no aluno e na construção e reconstrução de conceitos, consequentemente exigindo dos professores e alunos novas posturas. 


\section{Metodologia}

\subsection{Descrição da Pesquisa}

As estratégias e abordagens deste trabalho são resultados das experiências vivenciadas no Estágio Docente Supervisionado do curso de Química da Universidade Estadual da Paraíba como requisito obrigatório para o grau de licenciado em química.

A pesquisa foi desenvolvida em uma unidade de ensino fundamental e médio da rede de educação básica do estado da Paraíba, situada em um bairro periférico na Mesorregião do Agreste Central do Planalto da Borborema, em Campina Grande/PB. O trabalho foi realizado com 30 alunos, todos matriculados na $1^{\mathrm{a}}$ série do Ensino Médio, e com 2 docentes com formação superior concluída em Licenciatura Plena em Química. A escolha da escola ocorreu de forma aleatória levando em consideração aspectos como localização e aspectos sócio-econômicos da comunidade na qual a mesma encontra-se inserida.

O estudo teve caráter exploratório e investigativo, buscando conhecer a realidade educacional da escola e propor uma alternativa didático-pedagógica para minimizar a deficiência do ensino da Química Experimental. Utilizou-se como método, a pesquisa de abordagem qualitativa-descritiva, que de acordo com Ogliari [12], pesquisar é analisar informações da realidade que se está estudando, por meio de um conjunto de ações e objetivos, além de, uma comunicação entre os dados coletados e analisados com uma teoria de base.

\subsection{Problematização}

A química como qualquer outro ramo da ciência necessita de recursos didáticos que ofereçam a melhor forma de compreensão de um determinado tema em estudo. A educação química admite a constatação de que os princípios químicos estão presentes em vários aspectos da vida cotidiana. No entanto, a sofisticação e acessibilidade dos programas computacionais tornaram a interação homem-máquina muito mais rápida e familiar. Sendo assim, os indivíduos estão buscando a cada dia atualizar-se e possuírem o que há de mais inovador no âmbito da informática.

$\mathrm{Na}$ educação não pode ser diferente, os programas utilizados no ensino devem acompanhar a modernização, para que possam promover a maior interação possível entre o computador e o estudante, possibilitando-lhe também expressar o seu próprio saber para o desenvolvimento de suas tarefas [1].

Diversos pesquisadores $[6,8,9,11,13]$ vêm desenvolvendo trabalhos neste aspecto nas mais diferentes áreas do conhecimento, de modo a integralizar o uso dos recur- sos computacionais na educação.

No que se refere ao ensino de química, o processo de ensino-aprendizagem dos fenômenos químicos requer do docente que este se utilize de meios que possibilitem a visualização de tais fenômenos, seja pela imaginação e/ou comparação de aspectos abstratos com o real. Por exemplo, para o estudo da geometria assumida pelas moléculas, fundamentada na teoria da repulsão dos pares eletrônicos da camada de valência (VSEPR), o docente necessita introduzir a visualização das possíveis geometrias assumindo planos cartesianos tridimensionais. Sendo assim, a ausência de recursos didáticos pedagógicos ou computacionais pode causar desordem na visualização e consequentemente no entendimento da geometria molecular.

Outro aspecto importante é a realização de práticas experimentais que promovam a compreensão dos fenômenos químicos por meio da observação. Estas práticas além de proporcionar a interação entre os alunos, favorece a apropriação efetiva dos conceitos, enfatizando a problematização como ponto de partida para a construção do conhecimento. A experimentação possibilita que o aluno visualize os fenômenos através de uma ótica distinta daquelas mostradas nos livros. O problema é que a maioria das escolas não dispõem de laboratórios e/ou equipamentos que possibilitem a realização destas práticas.

Diante desta problemática e baseado na observação das práticas pedagógicas adotadas nas aulas de química, da infraestrutura e dos recursos didáticos disponíveis na instituição escolar em estudo, verificou-se a necessidade de implementar atividades experimentais (mesmo que virtualmente) de modo a promover melhorias no processo de ensino-aprendizagem.

Paritndo dos relatos dos docentes quanto ao grau de dificuldade vivenciado pelos discentes no que se refere à compreensão dos conteúdos pertinentes ao programa de química do $1^{\circ}$ Ano do ensino médio, introduziu-se nas aulas de química a utilização do software educacional Crocodile Chemistry para a realização de experimentos referentes aos conteúdos trabalhados em sala de aula.

A escolha do software educacional levou em consideração o objetivo da pesquisa (promover aulas experimentais), a disponibilidade do software e o recurso computacional de fácil manipulação.

O Crocodile Chemistry oferece uma biblioteca de componentes para construir uma maior interatividade com o aluno. Por exemplo, a biblioteca Química contém reagentes químicos diferentes classificados em diferentes categorias: metais, ácidos, bases, óxidos, haletos, sulfetos, carbonatos, nitratos, sulfatos, gases, etc. O acervo de vidrarias oferece ao usuário utensílios químicos 
diferentes, como: beckeres, frascos, erlenmayers, balões de fundo redondo, buretas, pipetas graduadas, etc. Além disso, a coleção de equipamentos inclui os aparatos necessários classificados em algumas coleções, como equipamentos e aparelhos, eletroquímica, medidores e sondas, sinais de segurança e rolhas.
A utilização do programa é simples devido obter uma interface gráfica de fácil entendimento utilizando comandos como "arrastar" e "soltar" para adicionar materiais e reagentes a área de trabalho. A Figura 1 apresenta o designer gráfico do software utilizado na pesquisa.
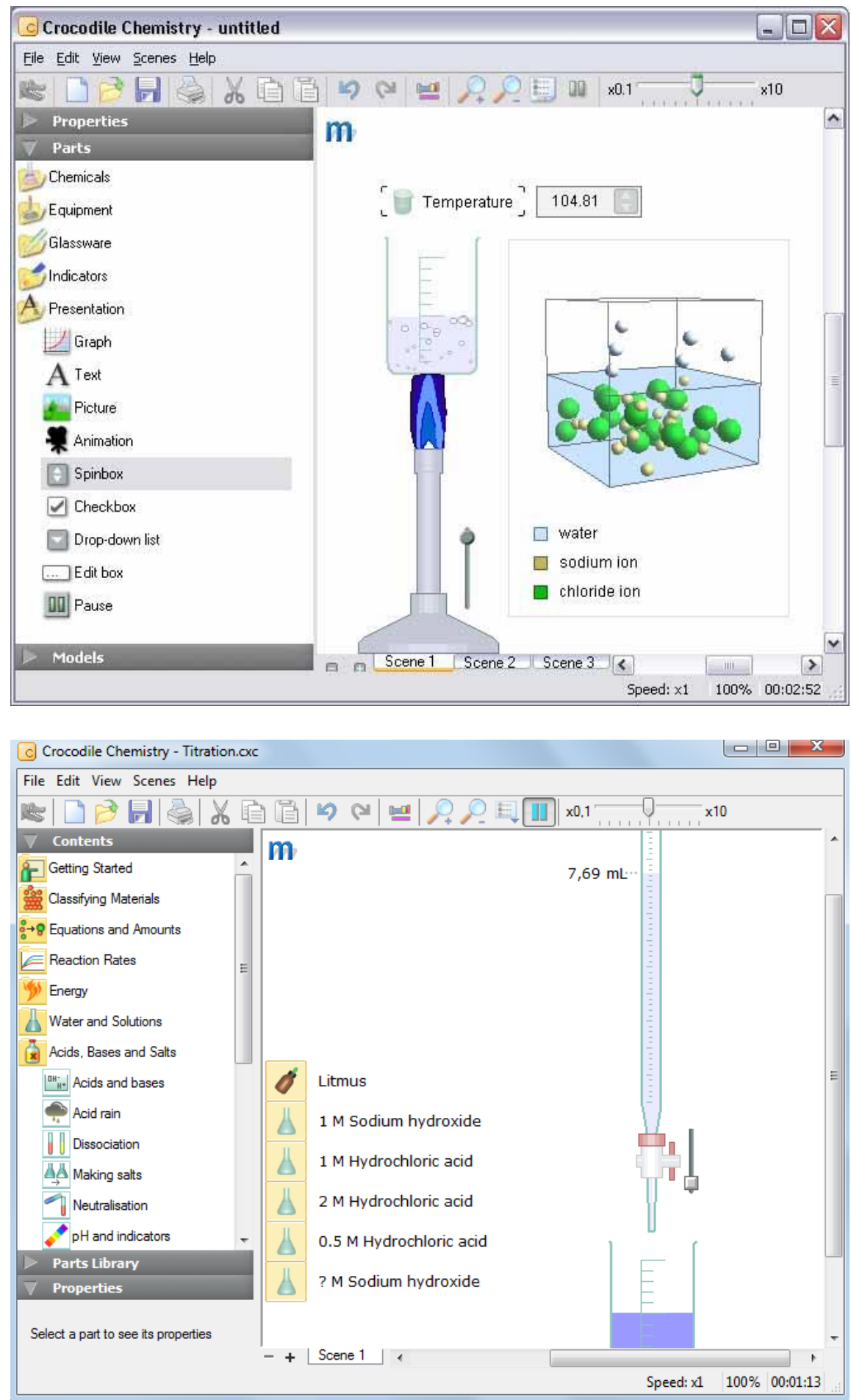

Figura 1. Designer gráfico do software Crocodile Chemistry 


\subsection{Aplicando o recurso virtual}

Inicialmente o software educacional foi instalado em 15 computadores pertencentes ao laboratório de informática da escola, através de uma licença gratuita para teste.

As simulações experimentais foram realizadas durante duas semanas consecutivas totalizando 6 (seis) aulas (45 $\mathrm{min} /$ aula), tendo sido precedidas de aulas teóricoexpositivas ministradas anteriormente. Em todo o proceso da pesquisa, houve a participação dos docentes da instituição, desde o planejamento até a aplicação do recurso computacional.

Para a realização das aulas teórico-experimentais foram criadas um roteiro contendo 4 (quatro) simulações de experimentos que envolvem a teoria relacionada a ementa do $1^{\text {a }}$ Ano do ensino médio, abordando as temáticas: estrutura atômica; processos de separação de misturas; reações ácido-base; e efeito da concentração nas reações químicas. $\mathrm{O}$ intuito principal era motivar a descoberta do conhecimento por meio da investigação experimental.

$\mathrm{O}$ procedimento metodológico baseou-se, primeiramente, em apresentar o fenômeno químico e, em seguida, construir as possíveis explicações para tal fenômeno. Após as considerações empíricas apresentadas pelos alunos, deu-se início a introdução de conceitos químicos e associação dos resultados observados nos experimentos com a teoria que fundamenta estas transformações. Por fim, juntamente com os alunos, gerou-se a conceituação química dos fenômenos estudados baseando-se nos resultados experimentais, na teoria abordada pelo livro didático e nas conclusões apresentadas. A Figura 2 apresenta o esquema metodológico utilizado.

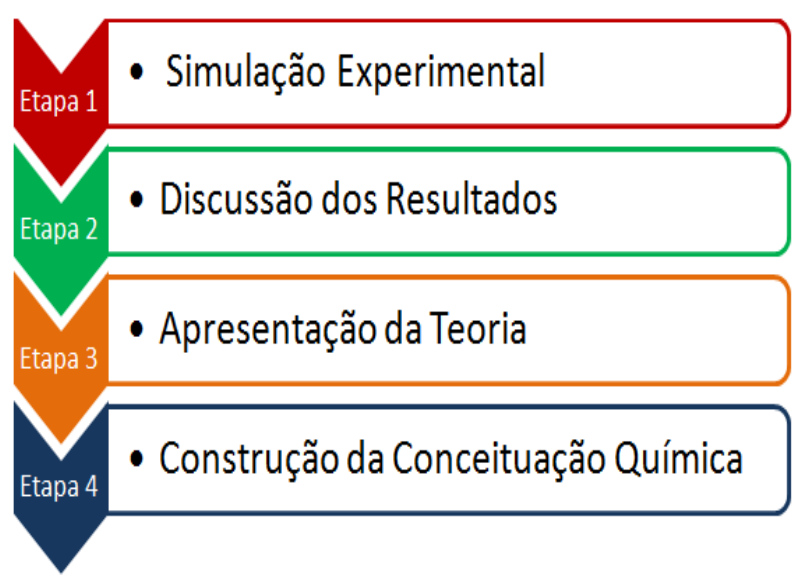

Figura 2. Esquema metodológico utilizado na prática educacional.

\section{Resultados}

\subsection{Avaliação do software pelos discentes}

Foi elaborado um questionário e aplicado ao fim das atividades a uma população de 30 alunos. Este teve a finalidade de conhecer a opinião dos alunos com relação ao software educacional utilizado. A sequência de questionamentos realizados está disposta na Tabela 2 .

Tabela 2. Sequência de questionamentos realizados durante a pesquisa

\begin{tabular}{c|l}
\hline $\begin{array}{c}\mathbf{N} \\
\circ\end{array}$ & \multicolumn{1}{c}{ Questão } \\
\hline $1^{\text {a }}$ & $\begin{array}{l}\text { A química é a ciência que estuda a matéria e suas } \\
\text { transformações. Na sua opinião qual o grau de } \\
\text { importância desta disciplina no ensino médio? }\end{array}$ \\
\hline $2^{\text {a }}$ & $\begin{array}{l}\text { A química é uma ciência experimental. Você } \\
\text { sente dificuldade em visualizar os fenômenos } \\
\text { químicos apresentados nos livros didáticos? }\end{array}$ \\
\hline $3^{\text {a }}$ & $\begin{array}{l}\text { Como você avalia a utilização do software Croco- } \\
\text { dile Chemistry nas aulas de química? }\end{array}$ \\
\hline $4^{\text {a }}$ & $\begin{array}{l}\text { Com relação ao grau de dificuldade em utilizar o } \\
\text { recurso computacional, como julgas? }\end{array}$ \\
\hline
\end{tabular}

Na Figura 3 são apresentadas as frequências das respostas obtidas.

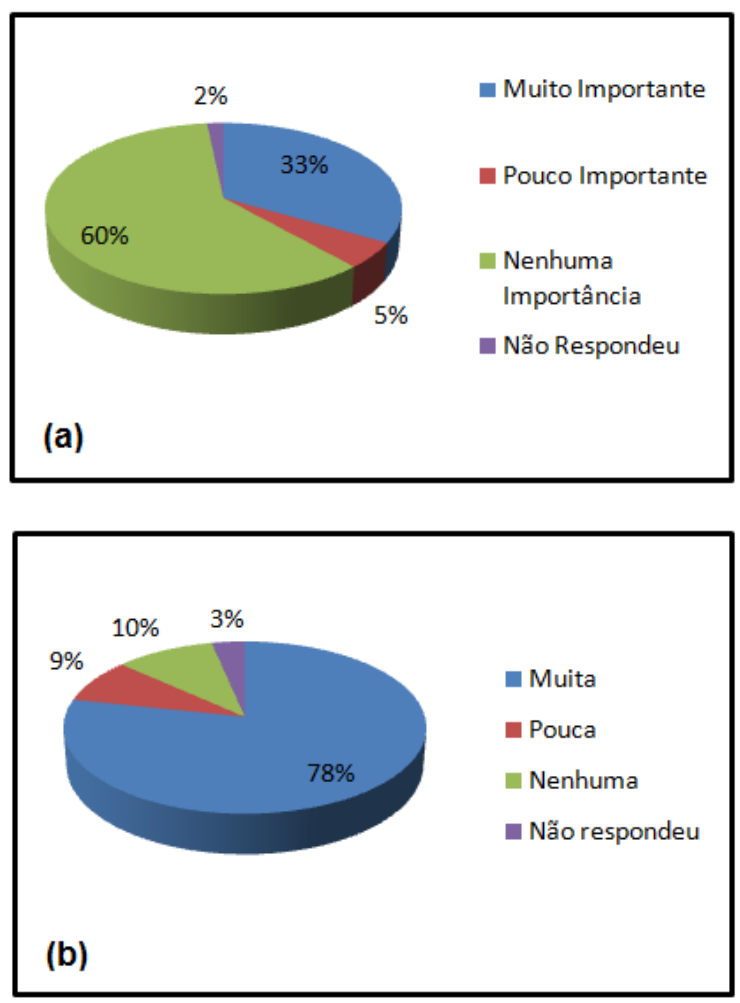

Figura 3. Importância da disciplina de química como matéria para o ensino médio (a). Grau de dificuldade de compreensão do conteúdo de química na sala de aula (b).

Como pode ser observado na Figura 3, dentre os as- 
pectos questionados, perguntou-se a respeito da importância da disciplina de química como matéria do ensino médio. Cerca de $60 \%$ dos entrevistados responderam que não vêem importância prática. Quando questionados sobre a compreensão do conteúdo trabalhado pelo professor nas aulas de química, 86,7\% dos alunos responderam que sente dificuldade de entendimento. Sobre as dificuldades, 77\% responderam que não conseguia compreender apenas pela discussão e pelo livro didático.

Estes resultados tornam-se preocupantes no que se refere à perspectiva esperada pelos discentes quanto à importância da disciplina de química para a formação intelectual do cidadão. Estes resultados podem estar associados às deficiências encontradas pelos docentes no que se refere à prática pedagógica, devido a ausência de laboratórios e recursos didáticos. Quando os alunos foram submetidos a perguntas em relação à avaliação da utilização de recursos computacionais como instrumento na construção do conhecimento químico, os resultados foram bastante positivos. A Figura 4 apresenta os dados obtidos.
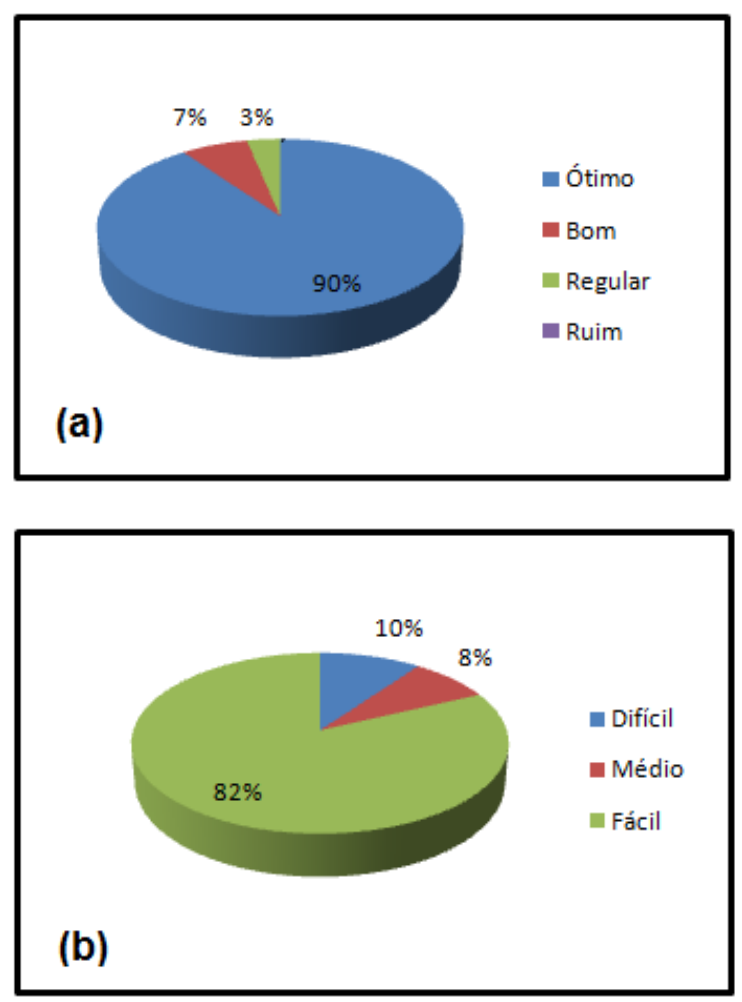

Figura 4. Grau de aprovação da utilização do laboratório virtual como recurso computacional nas aulas de química (a). Grau de dificuldade encontrado na utilização do software educacional (b).

É perceptível que a presença do recurso virtual proporcionou uma boa aceitação por parte dos discentes consultados.

De acordo com os dados mostrados na Figura 4 percebe-se que houve uma aprovação de $90 \%$. Isso prova que as atividades experimentais, mesmo que de forma virtual, provoca a curiosidade e estimula a descoberta da ciência pelos estudantes. Quanto à dificuldade de manipular o programa apenas $10 \%$ julgou ser difícil. Estes dados confirmam os estudos discutidos na fundamentação teórica deste trabalho.

\subsection{Avaliação do software pelos docentes}

Com o propósito de conhecer a realidade didáticopedagógica dos docentes consultados, estes responderam alguns questionamentos.

Quando perguntados a respeito dos recursos didáticos utilizados em suas práticas de ensino, percebeu-se que o método tradicional de ensino (quadro e giz) ainda é principal recurso utilizado. A Figura 5 apresenta os resultados obtidos.

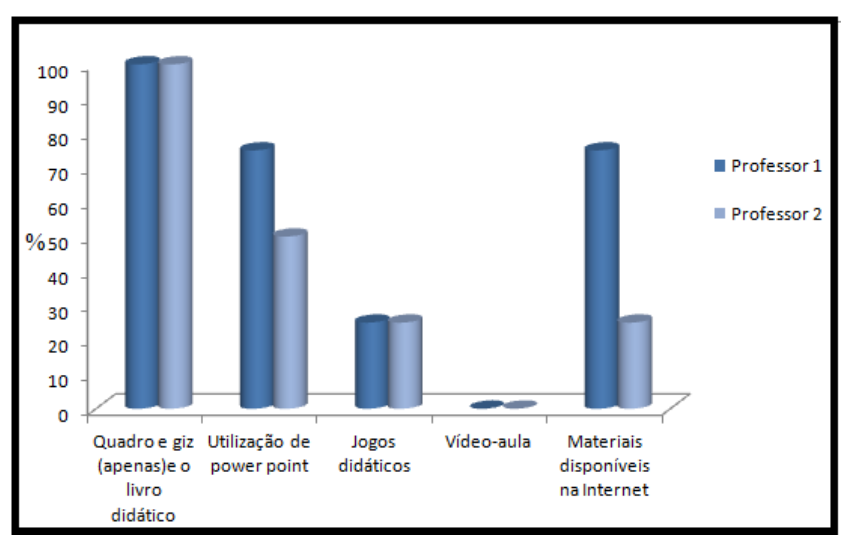

Figura 5. Recursos didáticos utilizados pelos docentes de química

Quando questionados sobre o conhecimento e o uso do recurso computacional aplicado ao ensino de química, ambos responderam que tinham conhecimento de softwares de simulação, mas não conheciam o Crocodile Chemistry. Julgaram ser muito interessante e motivador. Sobre este assunto, um dos consultados afirmou:

“... o uso de tecnologias na educação é capaz de mudar completamente a minha prática pedagógica no dia-a-dia com meus alunos, percebi como eles ficaram atentos $e$ curiosos com as descobertas no programa de química”.

\section{Conclusão}

A utilização das tecnologias computacionais da informação voltada para o ensino é, em geral, um recurso indispensável nas últimas décadas, porém, ao se tratar do ensino de química esta não é a solução efetiva para os problemas encontrados. As TICs são apenas ferramentas que proporcionam uma nova estratégia atrativa e eficiente no processo de construção do conhecimento químico. 
Com o intuito de apresentar uma proposta inovadora, a intenção do trabalho não foi substituir o professor pela máquina nem tampouco inserir o uso do software como a única solução para a problemática vivenciada pelas escolas em relação à ausência de laboratórios experimentais, mas mostrar a importância da construção do conhecimento mediante a realização de experimentos.

A partir dos objetivos deste trabalho, buscou-se verificar a eficiência da utilização de um laboratório virtual como recurso didático no auxilio do exercício à docência de química, mas precisamente no ensino da química experimental. Os resultados obtidos consolidaram as perspectivas deste trabalho. Através da observação e avaliação das atividades realizadas, verificou-se que, de fato, a inexistência de equipados laboratórios de química nas escolas é o principal fator que distancia a teoria da prática. Outro aspecto está relacionado com a ausência de propostas que minimizem esta deficiência.

Com este estudo, percebeu-se que a maioria dos discentes consultados demonstrou dificuldades de compreensão dos fenômenos químicos apresentados pelo livro didático, devido à ausência de atividades experimentais que facilitasse o entendimento. Em relação à proposta apresentada pelo trabalho, sugerindo a utilização de simuladores computacionais, está foi bem aceita e evidenciou um impacto positivo no processo educacional de química tanto pelos discentes. Quanto à facilidade e praticidade da utilização do software educacional, cerca de $90 \%$ dos consultados julgaram ser acessível. No que se refere à utilização do software como um atrativo para despertar a curiosidade e imaginação do alunado, percebeu-se uma boa participação e atenção destes quanto às atividades experimentais simuladas no laboratório virtual.

Mediante as considerações apresentadas percebe-se claramente que a incorporação de tecnologias computacionais no exercício da prática docente em química proporciona uma maior interatividade e facilita o processo de ensino-aprendizagem. No entanto, se faz necessário uma maior capacitação dos docentes para que seja possível a utilização de tais recursos. O processo de formação dos professores de química torna-se complexo, pois, exigem que o estudante possua conhecimentos básicos e específicos da ciência química além de conhecimentos de teorias educacionais, psicológicas, didáticas e sócio-humanas. A necessidade da introdução da informática no ensino de Química, na formação inicial de professores, possibilita a estes profissionais o desenvolvimento e aprimoramento de habilidades para o uso criativo das tecnologias computacionais em suas práticas educacionais. Neste sentindo, as instituições de ensino superior devem investir na formação dos novos docentes e proporcionar alternativas que garantam a formação continuada daqueles que estão atuando nas escolas.

\section{Agradecimentos}

Os autores agradecem a Secretária de Educação e Cultura do Estado da Paraíba pelo apoio concedido.

\section{Referências}

[1] G. M. P. Sousa. A informática como recurso didático para a aprendizagem de física no ensino médio. Dissertação de Mestrado. Universidade Federal do Rio Grande do Norte, 2007.

[2] V. M. Kenski. Educação e tecnologias: o novo ritmo da informação. Campinas: Papirus, 2007.

[3] J. Q. Ferreira. Ambientes virtuais no ensino superior de química: uso, aceitação e possibilidades de aprendizagem em uma disciplina de comunicação científica. Dissertação de Mestrado, Universidade de São Paulo, 2009.

[4] R. Gauche, R. R. Silva, J. A, Baptista, W. L. P. Santos, J. S. Mól, P. F. L. Machado. Formação de professores de química: concepções e proposições. Química Nova na Escola. 27:26-29, 2008.

[5] BRASIL, Secretaria de Educação Média e Tecnológica - Ministério da Educação e Cultura. Parâmetros Curriculares Nacionais. 1999

[6] B. Adalmango, A. G. Bishop, W. Adlong, D. R. Jr. Bedgood. Effectiveness of a Virtual Laboratory as a preparatory resource for Distance Education chemistry students. Computers \& Education. 53(3):853-865, 2009.

[7] J. L. A. F. Garcez, F. R. Maciel, V. M. B. Cardoso. Considerações ergonômicas para aplicação de mídia em ambientes educacionais para crianças do ensino fundamental. Produção. 22(2):284-295, 2012.

[8] E. S. N. Melo, J. R. F. Melo. Softwares de simulação no ensino de química: uma representação social na prática docente. Educação Temática Digital. 6(2):51-63, 2005.

[9] A. B. Pessoa. A Informática como instrumento mediador do ensino de química aplicada na formação inicial dos professores. Dissertação de Mestrado, Universidade de Brasília, 2007.

[10] R. C. Schank, C. Cleary. Engines for education.. New Jersey: Lawrence Erlbaum Associates, Inc. 1995

[11] W. S. Gabini, R. E, S. Diniz. Os professores de química e o uso do computador em sala de aula: discussão de um processo de formação continuada. Ciência \& Educação. 15(2):343-358, 2009. 
[12] L. N. Ogliari. Pesquisar é analisar dados: uma constante (re)construção da realidade. In: Galiassi, Maria do Carmo (org.) Construção curricular em rede na educação em ciências: uma aposta de pesquisa em sala de aula. p. 91-104. Ijuí: Unijuí, 2007.

[13] L. A. Ribeiro Junior, M. F. Cunha, C. C. Laranjeiras. Simulacão de experimentos históricos no ensino de física: uma abordagem computacional das dimensões histórica e empírica da ciência na sala de aula. Revista Brasileira de Ensino de Física. 34(4):4602(1-10), 2012. 